\title{
Acaso e método na pesquisa das poéticas da palavra cantada: um registro de caso
}

Leonardo Davino de Oliveira

\begin{abstract}
Resumo
$O$ artigo relata e discute um procedimento metodológico particular, utilizado pelo autor. No entanto, pela carência de meios de abordagens da questão das poéticas da palavra cantada, em particular a canção popular mediatizada, pode ser aproveitado por outros pesquisadores. O objetivo é mostrar como a coleta de dados ao acaso, pelo rádio, pode contribuir para a restituição da relação entre poesia e canção, por meio da integração de elementos como a presença do corpo na pesquisa e a relação amorosa do pesquisador com o objeto, articuladas à utilização de uma base teórica já testada e reconhecida.
\end{abstract}

Palavras-chave: canção, poesia, rádio, acaso, método. 
A pesquisa que venho desenvolvendo desde a minha graduação em Letras, e de que a minha dissertação de mestrado Pletora de alegria: a aventura frustra e reluzente do país mulato na poesia de Caetano Veloso significou o mais bem acabado resultado, despertou em mim, enquanto pesquisador de literatura e de canção popular mediatizada, a necessidade de verticalizar dados, teorias e dúvidas. Quando terminei o curso de mestrado, quando a dissertação estava para ser defendida, eu compreendi que a pesquisa estava apenas começando. Deparei-me com a sensação de vazio que acomete a maioria daqueles que findam um ciclo existencial. No caso, minha pesquisa sobre a obra do cancionista Caetano Veloso. Paralelo a isso, eu tinha dúvidas em relação ao projeto e ao processo de ingresso no doutorado, além da certeza de que eu estava muito longe de alcançar e desenvolver o conhecimento esperado para um pesquisador de canção. Campo do saber ainda bastante insipiente no Brasil, apesar da riqueza do corpus, e aglutinador de outras ciências: é preciso usar múltiplas chaves de leitura, tendo em vista os cruzamentos interdisciplinares. O objeto canção exige competências para as quais o pesquisador, envolvido exclusivamente com o objeto literário, não está preparado.

Propus-me então, como pretendia continuar trabalhando e pesquisando canção popular mediatizada, um desafio: analisar e publicar em um blog a primeira canção que eu ouvisse ao ligar o rádio. 365 canções, portanto, maturadas dia-a-dia. Uma amostra significativa e sintomática da canção difundida pelos meios de comunicação de massa. Sem contar que eu estaria entrando em contato com aquilo que o "povo" está ouvindo, sem que minhas escolhas (atravessadas por (pré)conceitos) atrapalhassem a coleta dos dados, que eu propunha que surgissem ao acaso: com engajamento do corpo.

Isso me possibilitaria tanto ouvir as "novidades", as novas composições, quanto perceber como algumas canções parecem permanecer fixas no cotidiano (sempre renovado) das pessoas, enquanto outras somem. Por que novos intérpretes, e até compositores-intérpretes, regravam "antigos" sucessos (ou não) e dão a estas canções novos significados, mediante a mudança da performance vocal? Que diferenças de significado cada nova leitura (gravação) de uma determinada canção traz? Quais compositores tocam mais nas rádios? Quais são os mais regravados? Estas e outras dúvidas, que destacarei mais adiante, estimularam a formulação do projeto e desenharam sua metodologia.

A proposta era ouvir e pensar a primeira canção que tocasse no rádio quando este fosse ligado, independente da hora do dia e de onde eu estivesse (em casa, ou na rua); reservar um tempo para sentar e articular as ideias surgidas a partir da audição daquela canção, também independente da hora e do tempo disponíveis, o que implicaria que alguns textos seriam maiores que outros, mais pela questão de tempo do que pelo fato de o objeto ser mais 
ou menos relevante; e postar em um blog a análise (o texto), a capa do disco em que a canção foi lançada e a letra dela. Além de armazenar tudo em um banco de dados, bem como cada canção (garimpada em sites de música e afins).

O acaso, obviamente, é limitado, para dizer o mínimo, no momento em que escolho uma única estação para manter o rádio (de casa, do celular, do computador e do automóvel) sintonizado. Pois, de antemão, ouvinte de rádio, escolhi uma estação em que é possível ouvir um raio maior e diverso dos matizes sonoros brasileiros. Eu precisava de uma estação que cobrisse o maior número de ritmos, compositores e intérpretes: cânones e novatos.

Aqui abro um espaço para contar que cresci ouvindo rádio. No interior da Paraíba de então, de onde venho, o sol nascia e morria ao som de repentistas e emboladores. A palavra cantada, portanto, desde cedo me acompanha e me intriga: afinal, que mistério tem a palavra cantada? Como pesquisador, que métodos eu posso criar para melhor abordar um objeto que é tão efêmero quanto, e aqui corro o risco de ser redundante, encantador? Para mim, enquanto criança, ouvir canção significava entrar em contato com o gosto das pessoas ao redor, pois, se todos, em diversas partes do mundo (para mim, criança, o mundo tinha outra dimensão) estavam ouvindo aquilo, no mesmo instante, era porque aquilo tinha alguma importância ontológica. Algo que me deslocava do individual para o coletivo: conectava-me com os outros.

Voltando ao meu desafio particular, decidi que o resultado desta investida seria o corpus da minha tese de doutoramento. Mas era preciso me impor critérios, mesmo, e talvez por isso, trabalhando com o acaso. Primeiro precisei aceitar o risco de permanecer trabalhando em setores em que minha competência de formação acadêmica é limitada: como a música e as artes plásticas. Demorei bastante tempo para me encontrar fazendo um curso de Teoria e Percepção Musical. Por outro lado, as capas dos discos, a contraparte visão do projeto, me cobravam atenção e leituras complexas sobre Semiótica da Cultura, entre outras. Tais lacunas eram resolvidas concomitantemente: à medida que os dias corriam, eu estudava a teoria e aplicava, de alguma forma, nas canções analisadas diariamente. Afinal, o exercício faz a interpretação e não pensar tudo com antecipação permite destravar o pensamento. Eu sabia que seria preciso modificar ou ampliar minhas perspectivas e certezas muitas vezes.

A canção hoje é matéria de estudo de várias ciências. $\mathrm{O}$ pesquisador, portanto, na impossibilidade de dominar todos os saberes, deve escolher campos de abordagens, mas não pode prescindir dos contatos. Daí o papel fundamental que exerce a leitura dos estudos na área da etnomusicologia, que integra musicologia e antropologia, por exemplo. Ela permite a investigação, entre outros aspectos, das vozes portuguesas, indígenas e africanas, além das imigrações, dentro do panorama da entidade sonora 
nacional brasileira. Seja como for, urgia a ultrapassagem (com prudência) das disciplinas particulares ao meu conhecimento.

E, além disso, havia ainda as disciplinas obrigatórias do curso de doutorado e os textos teóricos não apenas sobre canção, mas sobre literatura e filosofia, campos do saber que sempre atravessam meus pensamentos e meu trabalho. Tudo isso precisava fazer sentido dentro das análises diárias. Por outro lado, eu não poderia "pesar" (ser hermético) nas elucubrações teóricas e filosóficas, afinal meu público, já que o blog é aberto à visitação de qualquer interessado, poderia cobrar mais clareza e objetividade, como de fato em alguns momentos aconteceu. Ao mesmo tempo, eu não poderia me repetir, pois corria o risco de entediar e eu precisava do feedback, já que uma das minhas propostas era entender, também, o processo de recepção da canção mediatizada - aquela que "abole a presença de quem traz a voz e sai do puro presente cronológico, porque a voz é reiterável, indefinitamente, de modo idêntico" (ZUMTHOR, 2000, p. 14). Parti do pressuposto de que se algo canta é porque alguém quer ouvir e deve haver um motivo, mesmo inapreensível verbalmente (na escrita), para isso.

O blog é também um canal com outros ouvintes de canção, assim como eu, e não apenas um contato com meus leitores. Os canais informais de comunicação, mediados pelo computador, com o advento da internet, são fundamentais aos pesquisadores pela oportunidade de troca e discussão. Além de, muitas vezes, facilitar o acesso a determinados objetos. O desejo do Projeto 365 Canções surgiu exatamente da vontade de me testar diante da surpresa das canções que surgissem, mas também para sair da zona de conforto na qual, muitas vezes, nos colocamos.

Resolvi, assim, criar dois problemas principais que eu deveria responder ao longo dos 365 dias, a saber: a) responder à pergunta: que contribuição o curso de Letras pode oferecer ao estudo de canção, além da "simples" análise das letras?; e b) defender a premissa de que o cantor popular é uma neossereia na era da (re)produção e da mobilidade técnica.

Para resolver a primeira questão, precisei mergulhar na leitura de textos de autores que pensam a poesia para além da palavra escrita, tais como: Haroldo de Campos (1979), Octávio Paz (1982), Alfredo Bosi (1983) e Paul Zumthor (1998; 2000), entre outros. Era preciso estabelecer conjunções e disjunções entre os pensamentos destes autores e trazer os resultados para junto do meu pensamento, enriquecendo as possibilidades das análises das canções.

Já para desenvolver a minha segunda premissa era preciso um movimento verticalizado maior: a maturação diária das canções ouvidas e analisadas, a leitura atenta dos comentários deixados pelos leitores do blog e a separação, por critérios de 
regravações, recorrência de temas (paisagens ficcionais) e gestos estéticos.

Desde cedo eu sabia que não seria tarefa simples: ter a obrigação de escrever um texto inédito e estimulante (para quem lê e para mim, enquanto pesquisador na busca da solução das questões), diariamente (final de semana e feriados, inclusive), era enfrentar problemas como: falta de tempo, de ânimo, de gosto pela música ouvida e de ordem material.

Quanto ao gosto, de fato, na medida em que o tempo passa, ficamos mais exigentes. A academia nos impõe posturas que, muitas vezes, nos afastam, no mau sentido, do objeto analisado: a imparcialidade nem sempre traz bons resultados. A oportunidade de analisar canções que eu talvez, pelo gosto, não parasse para analisar, era assustadora e excitante: como ser imparcial e encontrar (ou não) elementos estéticos que singularizassem uma canção da qual eu não gostasse? Eis que me surpreendi revendo meu gosto: confirmando uns e mudando outros. O simples gesto de discernimento me deu a certeza de que o processo da pesquisa estava no caminho certo: trincar fórmulas preestabelecidas de entendimento do meu objeto.

Muitas vezes, "grávidos" de muita informação, passamos todo o curso para aplicar (praticar e exercitar) a teoria apenas no final do processo, nos chamados "trabalhos finais". Eu quis o caminho contínuo, a disseminação perene mais constante: saber seria o resultado das leituras, das audições e das escritas, diárias. Tudo atravessado por tudo: revisto todo dia.

Formular e defender a ideia de que o compositor popular é uma neossereia começou a se configurar no momento em que me dei conta de que eu poderia, aos poucos, ir separando as canções por temas, releituras (regravações) e informações que confirmassem minha suspeita. Parti, assim, do preceito de Paul Zumthor quando afirma que "o ponto de vista inicial que faz deslanchar o processo de confirmação, e, se aí couber, o de prova, é da ordem da percepção poética e não da dedução" (ZUMTHOR, 2000, p.11).

Em relação às regravações, importava, além do cotejamento, perceber as intenções, não apenas do intérprete, mas do novo sujeito que emergia da nova interpretação. Afinal, uma boa regravação é aquela que investe em pontos que outras gravações não tocaram. Ou seja, quem são os sujeitos, e quais são os sentidos que surgem a cada novo canto de uma mesma canção? Por outro lado eu perguntava às canções: o que as fazia ser sempre novas (e inéditas) para quem as ouve várias vezes? Se na poesia escrita há uma gramática interna singular, era preciso detectar o gesto entoativo singular também. Tentei cindir com a ideia de que haveria uma primeira (e melhor, haja vista servir de modelo) interpretação: há, defini para fins didáticos e metodológicos, o retorno ao mesmo, mas de forma diferenciada. Ou seja, as versões musicais são a verdade de cada voz atendendo a determinada ânsia de dado 
público-ouvinte. E aqui tento abolir a ideia de original e puro: "A pureza é um mito", como Hélio Oiticica grafou na instalação Tropicália, nos idos de 1967.

Era preciso, portanto desenvolver uma pesquisa paralela e complementar sobre as sereias. Ao mesmo tempo em que era preciso resistir ao poder encantador delas e da canção, que arrebata o pesquisador, embaçando sua percepção e levando-o a abandonar a análise. Urgia encontrar uma terceira margem: nem se amarrar ao mastro dos (pré)conceitos, nem tapar os ouvidos: não destruir meu objeto, gesto comumente praticado, mas deixá-lo cantar.

O episódio das sereias, cantado por Homero (2000) no "canto XII" da Odisséia, ocupa um espaço de particular importância na crítica literária e deve desempenhar importante lugar nos estudos de canção. Seja pelas referências filosóficas nele lançadas, seja pela força do mito em si: a ideia de um canto fundamental e fundador do ser.

A quantidade de textos que comentam este episódio é bastante grande. Minha pesquisa precisava ampliar tais abordagens fazendo uma comparação entre as leituras e as interpretações dadas ao público por Theodor Adorno e Horkheimer (1985) e, mais recentemente, Peter Sloterdijk (2003). Sem deixar de mencionar as leituras feitas por Franz Kafka (2002) e Maurice Blanchot (1984). Se "o poeta diz o que o povo quer ouvir", como o poeta Paulo Leminski declarou em entrevista ao Canal Brasil, penso que o compositor, por sua vez, canta aquilo que o povo quer ouvir. Daí a importância do cotejamento dos dados coletados que permite perceber a reincidência de casos.

Obviamente, para fins metodológicos e didáticos, parto de uma generalização - o compositor popular é uma neossereia - a fim de poder perceber as estratégias particulares de cada canção. Entre elas, a presença marcante da canção que canta a si mesma: "objeto olhante e olhado", como diria Roland Barthes (2003, p. 28). Ora, pensar sobre si, em um país com sérios problemas de identidade e aceitação como o nosso, problemas que, de fato, instituem nossa identidade, como o fazem as metacanções, implica na urgência da análise deste objeto. Nossa canção popular, por vezes, resgata o popular (tradições orais e folclóricas) de um isolamento profundo, promovido pela retórica de certa elite escrita. O cancionista percebe que preservar cegamente uma cultura, ou simplesmente desprezá-la, é uma perversão, em um país tão diverso quanto o Brasil. O cancionista assume função semelhante à da sereia de Ulisses: canta o passado, o presente e o futuro de nossas verdades. Ele assume para si a tarefa da cantar as dores e delícias do povo. Fica claro, assim, que a definição do termo "canção", na minha pesquisa, tem sua dimensão radicalmente ampliada: cantar à vida, a existência. 
Em carta a Peter Gast, Nietzsche (1888) vaticinou que "a vida sem música é simplesmente um erro, uma tarefa cansativa, um exílio". Tal afirmação ressoa em nós, ouvintes de música e de canções, quando percebemos o quanto esta linguagem artística está imbricada à nossa vida. Peter Sloterdijk, filósofo pós-nietzschiano, no livro Esferas I (2003), pensa o ventre materno (microesfera) como esfera sonora pré-natal, pois a mãe, em um nível mais profundo de sentido, canta a vida para o bebê. Ao mesmo tempo Sloterdijk observa que o desenvolvimento da capacidade crítica do espaço compartilhado leva o sujeito, enquanto adulto, a fechar os ouvidos. No entanto, o desejo de ser cantado não cessa. É aqui que entra a importância, por exemplo, dos artistas e, no meu trabalho, do compositor. Com ênfase na canção popular, daquela canção que toca no rádio, propus-me pensar os cancionistas como neossereias na era da reprodução técnica (BENJAMIM, 1980), visto utilizarem o ritmo já existente no mundo e em si para compor; além de conseguirem ter a sensibilidade de captar a necessidade do ouvinte e criar a experiência musical desejada. Ou seja, propus pensar, a partir das audições diárias, em como os compositores podem investir em dado aspecto, a fim de conseguir um determinado efeito no ouvinte, aproximando-os daquilo que Octávio Paz, em $O$ arco e a lira (1982), denominou de poeta: aquele que usa o "tempo e ritmo primordiais" para compor e engendrar, em quem ouve, a sensação de realinhamento (pertencimento) no mundo. $\mathrm{Ou}$, como Nietzsche (1992) definiu, a música como "afirmação da existência".

Os desvios filosóficos que empreendi, como se percebe, serviram para facilitar meu contato com o objeto. Inventariando os dados - as canções (letras e melodias) e as capas dos discos - concentrei minhas preocupações nas formas de separação, por campos de: metacanções e regravações. Não que as canções ouvidas se reduzissem a isso, mas estes seriam, ao final, os eixos temáticos e núcleos duros de minha tese. Aquelas canções que não se encaixavam eram separadas à espera de novos campos efetivamente significativos dentro do projeto.

A premissa teórica da metacanção abre o campo de investigação dos diálogos entre as canções: e, como pudemos perceber nos dados coletados, estes diálogos acontecem à mancheia. A metacanção (canção que come a si mesma) se desdobra para fora (toca outras canções ou outras linguagens estéticas) e para dentro (se autorreitera/questiona: letra e melodia). Algumas canções chegam a citar títulos, versos e melodias de outras canções, trabalhando com a herança cancional, além de apontarem para a consciência de que, se tudo já foi cantado, elas cantam sobre a impossibilidade de cantar (algo novo); enquanto outras empreendem discussão interna tão profunda da definição de si que promovem verdadeiros monólogos interiores. Sem dúvida, subjacente, percebi aqui uma das formas de como a área de Letras pode contribuir para as pesquisas de canção: seja pelo desenvolvimento dos estudos sobre 
paródia, pastiche e intertextualidade; seja pelas investigações da escrita de si e os limites da representação, por exemplo.

Como ouvintes, somos, em alguns momentos, metaouvintes: ouvimos o sujeito da canção ouvindo a si mesmo e ao outro: a própria canção cantar. Uma questão, importante, foi formulada por um leitor do blog: "e se uma canção se repetir?". Como a proposta era ter um banco de dados com 365 canções, resolvi o problema definindo que, caso, ao ligar o rádio, uma canção já lida/ouvida surgisse, eu passaria para a imediatamente posterior. Isso agradou a mim e aos leitores. Isso particularizava minha proposta.

Auerbach (1994) já apontou que somos reconhecidos pelas nossas cicatrizes, quando analisou o Ulisses homérico. Talvez a canção popular, pela pluralidade de temas e ritmos, consiga tocar nossas tais cicatrizes chamando atenção para a individuação do sujeito, mesmo, e talvez por isso, sendo canção popular e transmitida pelos meios de comunicação de massa: afinal, somos diferentes, mas estamos expostos aos mesmos apelos da existência. Aliás, como McLuhan (1969), um dos primeiros a analisar a questão, observou: a canção popular se cria na indústria cultural e de consumo: o meio acaba sendo a mensagem, ou parte dela.

Hoje em dia não é mais preciso comprar um disco para curtir uma canção, a não ser os colecionadores e os fãs. Basta comprar apenas as várias músicas de desejo e pronto: cada sujeito monta sua trilha sonora particular. Daí a importância de coletar, publicar e guardar as imagens das capas dos discos cujas canções surgissem. Vale ressaltar que a audição de mais de uma canção, de um mesmo disco, aconteceu. Mas, como nosso investimento analítico era prioritariamente sobre canção, não vimos nenhum problema nisso. Esta relação com as imagens permitiu, de viés, entrar em contato com a cristalização de tempos e espaços: discos "antigos" e "novos" apontando para a fotografia dos instantes em que foram lançados, até porque, "o espaço em que se desenrola a voz mediatizada torna-se ou pode se tornar um espaço artificialmente composto" (ZUMTHOR, 2000, p. 14). A capa fixa o instante.

Paralelamente a isso, pude constatar que a distância relacional entre o público e o artista está muito menor, no sentido de mais próxima e acessível. As possibilidades são enormes: a internet explode cada vez mais, e com mais recursos e eficiências, as fronteiras de separação. Assim como as soluções de feitura e de divulgação de uma canção. E, acredito, em um futuro próximo, a renda do artista virá das apresentações e dos produtos paralelos ao disco (este objeto de desejo) propriamente dito. Porém, eu não saberia precisar o nível de vantagem ou desvantagem para cada parte envolvida - cancionista / gravadora / ouvinte.

Importa lembrar que a canção popular brasileira há muito rompeu com a distinção entre arte democratizada e arte de elite grafocêntrica. Letra de música não é poesia, e nem quer (nem deve 
querer) ser, isto já está claro. Embora uma atividade atravesse a outra, reciprocamente, o que a canção transmite "é percebido pelo ouvido (e eventualmente pela vista), mas não pode ser lido propriamente, isto é, decifrado visualmente como um conjunto de signos codificados da linguagem" (ZUMTHOR, 2000, p. 15). O pesquisador de canção, de formação em Letras, deve criar novos meios de ouvir, avaliar e interpretar canções: incluindo re-historicização e re-espacialização do objeto. A história da canção (como toda a História) é um exercício de ficção. Cada autor/pesquisador investe em determinado interesse ou aspecto, por ora considerado relevante.

Processo intrinsecamente inacabado e permanente, a pesquisa não pode prescindir das questões que a motivaram à custa do pesquisador perder o foco de seus objetivos. Cabe a ele fazer o movimento que vai da pesquisa básica, geradora de conhecimentos novos e úteis, ao avanço da ciência, no estabelecimento de novas diretrizes, métodos e meios. Incipientes, os estudos de canção no Brasil precisam de modelos e solicitam olhares novos e livres para o seu imenso potencial: seja pela variedade de ritmos, seja pela convergência de temas, entre outros motivos.

Parti da premissa quantitativa das 365 canções, surgidas ao acaso, para criar uma amostragem de informações estéticas, com o objetivo de apontar não só o panorama daquilo que é ouvido hoje, através das frequências modulares, mas, principalmente, da qualidade do nosso cancioneiro popular: por meio da observação sistemática.

Quantificar não significa reduzir ou enquadrar os dados, mas, ao contrário, no caso da pesquisa de canção, a possibilidade de cotejar e ler as filigranas do objeto: classificá-lo e organizá-lo. Temas, sujeitos, arranjos, implicamentos da composição (letra e melodia) são alguns dos recursos de distinção estatísticos a ser utilizados pelo pesquisador, no processo de determinar a ocorrência (ou recorrência) dos fenômenos. Daqui se configura a pesquisa qualitativa: aquela que estabelece as relações dinâmicas entre os dados coletados e entre o arcabouço teórico do pesquisador e seu objeto.

Manter a dúvida, tal qual o filósofo, muito mais do que achar uma verdade, é o compromisso do pesquisador que participa do levantamento, que se deixa tocar pelo objeto, sem deixar de interrogar diretamente este objeto na expectativa de cumprir os objetivos preestabelecidos. Desde que não limite o conhecimento - e um objeto como a canção, pelo poder encantador pulsante, facilita isto - a mero encaixe do objeto em quadros estanques. $\mathrm{O}$ objeto precisa ser cantado, mas também precisa cantar. A experiência do canto, ou melhor, a escrita do acontecimento da experiência do canto é apenas um dos registros necessários para o desenvolvimento do saber. 
A resposta para a pergunta "o que pretendo abordar?" precisa e deve ser enfrentada continuamente. Ainda mais quando o objeto aparece sem que nós tenhamos, a princípio, qualquer domínio sobre ele: assim é a canção popular, que faz parte do exercício diário da vida; emoldura momentos afetivos das formas mais variáveis possíveis, atendendo a diversos apelos do indivíduo.

Provar que o cantor popular é neossereia significou eleger, em detrimento de outros aspectos igualmente importantes, uma parcela limitada das possibilidades de ação sobre o objeto: seja por causa do tempo de duração de um curso de doutorado, seja pelo espaço físico limitado onde os resultados da pesquisa serão depositados: a tese.

Para tanto, utilizando o gesto barthesiano de "saber com sabor", é imprescindível que o pesquisador se apaixone pelo objeto, mesmo que, aos poucos, à medida que o processo decorra, o efeito da porção amorosa se desfaça: para tristeza tanto do objeto, quanto do pesquisador e do resultado da pesquisa. O risco do desencanto precisa ser encarado. Limites e restrições vão desenhando o surgimento dos capítulos, pois há prazos a ser cumpridos: o resultado "final" da pesquisa.

Obviamente, alguma coisa, ou muito, do que se pretendia investigar ficará de fora e/ou perderá força no meio do caminho. Isso não significa falhas, pelo contrário, quando bem administradas, as perdas das certezas disparam novos caminhos, mais eficazes para o momento.

Pesquisar é procurar respostas para inquietações, ou para um problema, que incita o pesquisador: no meu caso, como o curso de Letras pode ajudar no estudo de canção? E como argumentar e desenvolver a ideia de que o compositor popular (mediatizado) é uma neossereia, ou seja, diz (canta) aquilo que o ouvinte quer ouvir?

Eu disse acima que a canção necessita de teorias e práticas de investigação e afirmo, sem me contradizer, que o número de livros, sites e outros produtos que tem a canção como mote é enorme. Há, sem dúvida, um interesse claro no tema. Afinal, como também já afirmei acima, a canção é parte integrante de nossa existência. Porém, para o pesquisador que queira chegar a outras camadas, para além da simples descrição e paráfrase, é preciso revisar com atenção a literatura existente sobre a questão. Já é possível encontrar livros que facilitam diversos tipos de abordagens do assunto. Cabe ao pesquisador fazer as escolhas que melhor atendam às suas necessidades momentâneas, sem perder de vista o senso crítico: o mesmo discernimento que ele aplicará sobre o objeto, ele deve aplicar sobre aquilo que já se escreveu e foi publicado sobre o assunto. Só assim o pesquisador de poéticas da palavra cantada, ou de qualquer área do conhecimento, poderá, não só observar as lacunas existentes, mas também propor soluções para elas. $\mathrm{Ou}$ 
seja, é a revisão - teórica, empírica, histórica - que determina as diretrizes do futuro da pesquisa, bem como os resultados desta.

A formulação adequada do problema a ser solucionado mantém tênue relação com os objetivos esperados. Neste momento, da montagem do projeto, pensei na relevância daquilo a que me propunha pesquisar, ou seja, qual era minha intenção com esta pesquisa, bem como investi na síntese dos caminhos a que os estudos de canção poderiam me levar. Se meu objetivo geral era provar minha tese, eu precisava de objetivos específicos que auxiliassem meu intento. Eram estes objetivos que me explicitariam os detalhes e o desdobramento da minha ideia inicial e geral.

Precisei esboçar objetivos específicos na feitura do projeto, mas estes só começaram a ser marcados quando o processo, concomitante, de audição e leitura já estava em andamento. Saber quais os resultados que pretende alcançar ou qual será a contribuição significativa da pesquisa é ação que só se configura efetivamente no processo de captação das amostras acidentais, pelo menos foi assim no meu caso.

Com custo financeiro relativamente barato, a pesquisa de campo e a coleta de dados, por outro lado, forçam certo isolamento do pesquisador. Nada que cause espanto em um mundo onde cada indivíduo-ouvinte pode levar sua sereia particular no bolso, basta ter um celular e acessar uma estação de rádio, ou baixar as músicas que bem quiser (aquelas que melhor cantem o ouvinte) e montar uma trilha sonora pessoal e intransferível.

Esta imposição do objeto deve ser enfrentada com a ida, sempre que possível, a espaços onde a canção possa ser consumida "ao vivo", ou onde ela repouse guardada: daí a importância dos shows (de onde os artistas têm tirado seus sustentos, com a crescente defasagem do mercado das gravadoras de disco), espaços de contato direto não só com o cancionista e sua performance, mas também com o público que, assim como o pesquisador, a princípio, consumiu a canção pelo rádio: o show é a percepção do canto pelos cinco sentidos; além de lugares como museus e institutos que trabalham com a preservação da memória da palavra cantada, fonte de muitos cancionistas contemporâneos. $\mathrm{O}$ pesquisador de canção precisa, portanto, sair da zona de conforto, segura, mas limitadora, do fone no ouvido e deixar o corpo se embalar e transpirar na busca de pensamentos corajosos que estimulam (e/ ou confirmem) a construção de hipóteses.

Neste momento entra também o trabalho laborioso do pesquisador em distinguir quais procedimentos são empregados no estudo de problemas semelhantes ao seu e como tais fatores afetam nos resultados. Mais uma vez surge a importância da revisão bibliográfica. Ela mostra a evolução dos conceitos dentro do estudo de determinado objeto e aponta para a obtenção de informações sobre a situação atual do tema em pesquisa. 
Para tabular e apresentar os dados de 365 canções, devido à diversidade de informações, foi imprescindível a anotação e a notação diária, que iluminaram os resultados do processo dentro do processo. $\mathrm{O}$ aspecto final depende da organização, desde o princípio, da coleta. O computador, com os vários recursos disponíveis (elaboração de tabelas e índices), facilita na armazenagem, mas cabe ao pesquisador cotejar, separar e direcionar os dados.

A organização facilita a interpretação e a análise: momentos em que o pesquisador estabelece relação entre aquilo que foi coletado e os objetivos do projeto. De fato, nenhuma canção deixou de ter significado: se tivéssemos a possibilidade temporal e espacial de ilimitar nosso arco investigativo, mas é preciso rejeitar ou confirmar objetivos. Retornar aos pressupostos que motivaram a pesquisa facilita a síntese dos resultados.

Os excedentes, ao contrário do que possa parecer, não atrapalham o resultado final. Pelo contrário, eles apontam que a pesquisa conseguiu progredir e tais "sobras" significam que o objeto ainda tem frentes de abordagens a ser investigadas, por outros pesquisadores, ou pelo mesmo pesquisador, noutro momento. $\mathrm{Ou}$ seja, os excedentes revigoram a pesquisa científica.

Meu gesto aqui teve a intenção de esboçar um percurso, o qual se desenvolveu como metodologia, ainda (e sempre) em estado de progressão, sobre a importância dos estudos do papel da canção (da palavra cantada) popular mediatizada dentro dos cursos de Letras: colocando-me como pesquisador e ouvinte. Dito isto, este trabalho pretende contribuir para mostrar caminhos que diminuam a carência de métodos de abordagem da canção; investir na reconciliação entre poesia e canção, já que o estudo desta pode oferecer àquela o caráter original (retorno) de ser percebida pelos cinco sentidos; e, como ambição pessoal, chegar a comprovar a tese de que o cancionista popular é uma neossereia na era da reprodução e da mobilidade técnicas. A ambição é grande; os riscos também; mas o desejo e a vontade são maiores.

\begin{abstract}
The paper reports and discusses a particular methodological procedure used by the author. However, the lack of media approaches the issue of poetic singing words, particularly the popular song the media, can be used by other researchers. The goal is to show how data collection at random, by radio, can help to restore the relationship between poetry and song, through the integration of elements such as the presence of the body in search and loving relationship between the researcher
\end{abstract}


and the object, articulated the use of a theoretical base has been tested and recognized.

Keywords: song, poetry, radio, random, method.

\section{REFERÊNCIAS}

AUERBACH, Ereich. Mímesis. São Paulo: Perspectiva, 1994.

ADORNO, Theodor W.; HORKHEIMER, Max. Dialética do esclarecimento. Trad. Guido Antonio de Almeida. Rio de Janeiro: Jorge Zahar, 1985.

BARTHES, Roland. Aula. São Paulo: Cultrix, 1980. Crítica e verdade. São Paulo: Perspectiva, 2003.

BENJAMIM, Walter. A obra de arte na época de suas técnicas de reprodução. In: BENJAMIM, Walter. Os pensadores. São Paulo: Abril Cultural, 1980.

BLANCHOT, Maurice. O livro por vir. Trad. Maria Regina Louro. Lisboa: Relógio d'Água, 1984.

BOSI, Alfredo. O ser e o tempo na poesia. São Paulo: Cultrix, 1983.

CAMPOS, Haroldo de. Rupturas dos gêneros na Literatura Latino-americana. In: MORENO, C. F. (org.). América Latina em sua Literatura. São Paulo: Perspectiva, 1979. p. 281-305.

DIAS, Márcia Tosta. Os donos da voz: indústria fonográfica brasileira e mundialização da cultura. São Paulo: Boitempo Editorial, 2000.

ECO, Umberto. Apocalípticos e integrados. São Paulo: Perspectiva, 2001.

HOMERO. Odisséia. Trad. Carlos Alberto Nunes. Rio de Janeiro: Ediouro, 2000.

KAFKA, Franz. O silêncio das sereias. In: Narrativas de espólio. Trad. Modesto Carone. São Paulo: Companhia das Letras, 2002.

McLUHAN, Marschall. Os meios de comunicação como extensão do homem. São Paulo: Cultrix, 1969.

NIETZSCHE, Friedrich. Cartas a Peter Gast. Nice, 15 de janeiro de 1888.

O nascimento da tragédia ou Helenismo e pessimismo. São Paulo: Companhia das Letras, 1992.

PAZ, Octavio. O arco e a lira. Rio de Janeiro: Nova Fronteira, 1982. . Os Filhos do barro. Rio de Janeiro: Nova Fronteira, 1984.

SLOTERDIJK, Peter. Esferas I - Burbujas. Madrid: Siruela, 2003. TATIT, Luiz. A canção: eficácia e encanto. São Paulo: Atual, 1986. . O cancionista: composição de canções no Brasil. São Paulo: EDUSP, 1996. 
ZUMTHOR, Paul. Introdução à poesia oral. São Paulo: Educ, 1998. . Performance, recepção e leitura. São Paulo: Educ, 2000. 